\title{
Enhancing safe routes to school programs through community-engaged citizen science: two pilot investigations in lower density areas of Santa Clara County, California, USA
}

Nicole M. Rodriguez ${ }^{1}$, Alisa Arce², Alice Kawaguchi², Jenna Hua', Bonnie Broderick², Sandra J. Winter ${ }^{1}$ and Abby C. King ${ }^{1,3,4^{*}}$ (D)

\begin{abstract}
Background: While promoting active commuting to school can positively affect children's daily physical activity levels, effectively engaging community members to maximize program impact remains challenging. We evaluated the initial utility of adding a technology-enabled citizen science engagement model, called Our Voice, to a standard Safe Routes to School (SRTS) program to enhance program engagement activities and student travel mode behavior.

Methods: In Investigation 1, a prospective controlled comparison design was used to compare the initial year of the Santa Clara County Public Health Department's SRTS program, with and without the Our Voice engagement model added, in two elementary schools in Gilroy, California, USA. School parents served as Our Voice citizen scientists in the SRTS + Our Voice school. In Investigation 2, the feasibility of the combined SRTS + Our Voice methods was evaluated in a middle school in the same district using students, rather than adults, as citizen scientists. Standard SRTS program engagement measures and student travel mode tallies were collected at the beginning and end of the school year for each school.
\end{abstract}

Results: In the elementary school investigation (Investigation 1), the SRTS + Our Voice elementary school held twice as many first-year SRTS planning/encouragement events compared to the SRTS-Alone elementary school, and betweenschool changes in walking/biking to school rates favored the SRTS + Our Voice school (increases of 24.5\% vs. 2.6\%, $P<.001)$. The Investigation 2 results supported the feasibility of using students to conduct SRTS + Our Voice in a middle school-age population.

Conclusions: The findings from this first-generation study indicated that adding a technology-enabled citizen science process to a standard elementary school SRTS program was associated with higher levels of community engagement and walking/biking to school compared to SRTS alone. The approach was also found to be acceptable and feasible in a middle school setting.

Keywords: Active transport, School health, Children, Safe routes to school, Citizen science, Built environment, Walking, Bicycling, Transportation, Community engagement

\footnotetext{
* Correspondence: king@stanford.edu

${ }^{1}$ Stanford Prevention Research Center, Department of Medicine, Stanford

University School of Medicine, Stanford, CA 94305, USA

${ }^{3}$ Division of Epidemiology, Department of Health Research and Policy,

Stanford University School of Medicine, Stanford, CA 94305, USA

Full list of author information is available at the end of the article
}

(c) The Author(s). 2019 Open Access This article is distributed under the terms of the Creative Commons Attribution 4.0 International License (http://creativecommons.org/licenses/by/4.0/), which permits unrestricted use, distribution, and reproduction in any medium, provided you give appropriate credit to the original author(s) and the source, provide a link to the Creative Commons license, and indicate if changes were made. The Creative Commons Public Domain Dedication waiver (http://creativecommons.org/publicdomain/zero/1.0/) applies to the data made available in this article, unless otherwise stated. 


\section{Background}

During the past $30-40$ years, daily physical activity levels among U.S. youth have gradually declined [1]. Walking to school, in particular, decreased from 41 to $13 \%$ between 1969 and 2001 [2], with only 35\% of children in grades K-8 living within one mile of school reporting usually walking/biking to school [3]. This trend continues despite the fact that walking/biking to school contributes to healthy daily levels of physical activity [4]. Safe Routes to School (SRTS)--a national program promoting safe options for walking/biking to school [5]--has been shown to increase physical activity among school-aged children through supporting bicycle and pedestrian education, school wellness policies, and engineering improvements $[6,7]$. U.S. government initiation of SRTS began with two funded pilot projects in 2000, which quickly led to the growth of grassroots SRTS activities throughout the U.S. [8]. The U.S. SRTS model is built on the "Five E's" concept: education, encouragement, evaluation, enforcement, and engineering [5].

A key though often challenging aspect of SRTS program adoption and sustainability is initial and ongoing engagement among residents and community stakeholders. For example, promoting collaborative community-research partnerships has been reported to be a key program adoption strategy related to successful SRTS program adoption in Canada and the U.S. [9]. However, in an educational climate of increasing fiscal constraints, finding efficient methods for building such collaborative partnerships can be difficult. This is despite reports that investments in programs and infrastructure that facilitate walking and biking to school have the potential for reducing transport expenditures for school districts and families [10].

The first-generation investigations described in this article evaluated an evidence-based community citizen science approach, called Our Voice [11], for increasing community member and stakeholder engagement and retention in a local public health department-sponsored SRTS program which was being initiated in Gilroy, California, USA. The Our Voice approach combines the active community engagement of community-based participatory research with the standardized resident-based data collection methods that are a hallmark of citizen science [11]. The term "citizen science" refers to actively engaging local residents in gathering, analyzing, and utilizing data to improve community health and wellbeing [11]. In the Our Voice approach, residents learn to use the Discovery Tool (DT), a mobile environmental assessment app, to capture their walking route and take geo-coded photos and record audio-narratives of barriers and facilitators to health and wellbeing in their communities [12]. The DT (described below) is the first step in a multi-phase Our Voice citizen science process that includes data-driven community discussion and topic prioritization, and resident activation through advocacy with local stakeholders [11, 13-18]. While Our Voice has been employed successfully in a growing number of U.S. and global sites to improve local environments for physical activity and other health-enhancing behaviors [11, 15, 19], this is the first systematic application of Our Voice to school settings.

In Investigation 1 of this study, two elementary schools (grades kindergarten through grade 5) were compared, one with Our Voice added to the Santa Clara County, California Public Health Department's (SCCPHD) standard SRTS program and one with the SRTS program alone. The major study question concerned whether SRTS + Our Voice was associated with increased school-wide SRTS engagement activities and greater changes in the number of students walking/biking to school relative to SRTS-Alone. SRTS program engagement activities continued to be tracked during the subsequent year to assess how well the activities begun in the initial SRTS year were maintained.

Additionally, since school districts in the U.S. often include both elementary schools (kindergarten through grades 5 or 6 ) and intermediate or middle schools (grades 6 or 7 through grade 8) [20], we explored the initial acceptability of including the citizen science engagement model in a SRTS program being initiated in a middle school in the same district (Investigation 2). The objective of Investigation 2 was to assess the initial feasibility and acceptability of the combined SRTS + Our Voice methods in a middle school setting when using middle school students themselves (rather than parents) as the citizen scientists.

\section{Methods}

\section{Study location}

Gilroy, California (total population $=53,231$ in 2015) [21] a lower density region of Santa Clara County, Californiaconsists largely of farmland and suburban areas. High school graduates or higher represent $77 \%$ of the population, while $15 \%$ of the population lives in poverty [21]. Fifty-eight percent of residents self-identify as Hispanic/Latino, 32\% identify as non-Hispanic White, and 26\% are foreign-born. There are 18 public schools in the Gilroy Unified School District, which enrolls about 11,225 students [22].

In 2015, parental attitude and behavior survey data were gathered on 4117 parents across 12 Gilroy district schools by the Santa Clara County Public Health Department (SCCPHD) Safe Routes to School program, using forms from the National Center for Safe Routes to School (http:// archive.saferoutesinfo.org/data-central). While, overall, many families living in the school district (54\%) reported living within walking or biking distance from school, most families (69\%) drove their children to school. Walking (19\%), school buses (5\%), carpools (4\%), and biking (2\%) were low. Reasons parents provided for not allowing their children to walk/bike to school included concerns about safety of intersections (54.8\%), distance (54.5\%), traffic 
speed (51.5\%), violence/crime (51.4\%), and traffic amount (48.7\%) [23].

In 2015, investigators from Stanford University partnered with the Santa Clara County Public Health Department (SCCPHD) to conduct an initial evaluation of the Our Voice citizen science approach as an addition to SCCPHD's SRTS program.

\section{Investigation 1: Comparison of elementary schools with and without Our Voice}

\section{Design and school site selection}

A prospective controlled comparison design was used. During September 2015, SCCPHD staff identified, with assistance from the Gilroy Unified School District, the next two Gilroy elementary schools that were ready to initiate SRTS for the first time. Given that the two schools were on somewhat different time tables for initiating SRTS activities, School A (which was ready to initiate SCCPHD's SRTS activities in late September 2015) was chosen to receive the SRTS + Our Voice program, while School B (which was ready to initiate SRTS activities in November 2015) received SRTS-Alone.

At Elementary School A (SRTS + Our Voice), six local adult "citizen scientists" were recruited through school parent-teacher groups and school staff meetings. At Elementary School B, standard SRTS data collection was conducted by SCCPHD staff with assistance from five parent and community volunteers. Human subject approvals were obtained from the Institutional Review Boards (IRBs) at Stanford University and SCCPHD.

\section{SRTS program intervention activities}

The SRTS intervention program typically begins with a standard set of observational evaluations of the local environment. SRTS program walkability/bikeability observations [24], conducted in Fall 2015 by SCCPHD staff and several community members, included observational surveys of student pedestrian and bicycle helmet and safe riding behaviors, and environmental observation audits (i.e., evaluating features facilitating or hindering safe walking/biking). At both sites, the pedestrian/bicyclist observational surveys were conducted as part of standard SRTS practice in this locale [24]. In contrast, collection of the SRTS environmental observation audit data differed between the two schools. At the SRTS + Our Voice site, the SRTS environmental observation audit tool was replaced with the DT mobile app. It was hypothesized that this app would allow community members to document relevant environmental barriers and facilitators in more depth by using photographs and personal narratives to contextualize resident observations.

Six parents at School A were trained to conduct DT assessments (lasting 30-45 min each) on two mornings prior to school start during one week in September
2015. DT walking zones were selected by a team of SCCPHD staff and community members and focused on areas most frequently used by students traveling to school. Participants were given a prompt to capture aspects of their environment that made it easier or harder to walk/bike to school and were asked to take photos and accompanying audio narratives in their designated zones. DT training required less than $10 \mathrm{~min}$ and was accomplished just prior to its use.

At School B, the typical SRTS environmental audit tool was used instead of the DT [24]. This audit tool includes 50 questions measuring the following eight factors on a scale of 1 to 7 , with 7 classified as a serious problem: room to walk, ease of street crossing, room to bicycle, ease of bicycling, parent support, driver behaviors, safety, and pleasantness/aesthetics. Auditors check off and rate each item as they walk in their designated zones. Five adult community members (three parents and two after-school staff) participated in the assessments along with SCCPHD staff. Assessments lasted approximately 30-45 min and were conducted in the morning prior to school start on two days within the same week as School A. As with the selected DT zones, the environmental assessment zones for School B were selected by a team consisting of SCCPHD staff along with members of the school community and focused on areas most frequently used by students coming to school.

\section{Community meetings to discuss the environmental audit information}

In School A, following DT use, standard Our Voice methods were deployed, including two community meetings where citizen scientists categorized data, prioritized issues, and advocated with stakeholders for realistic changes related to those identified issues [11]. The community meetings, facilitated by SCCPHD, were held 1-2 months after the DT walks. At the first meeting, each participant received a data packet with printed photographs and transcripts from their DT walks that had been transcribed by the research team. Citizen scientists thematically categorized their data within a theme, for example, traffic, crosswalks, stop signs, safety, and pathways. After thematically categorizing their data, participants ranked the themes based on importance and feasibility. Relevant local stakeholders were also identified for subsequent engagement (e.g., school administrators, public works engineers).

At the second meeting with community stakeholders, the citizen scientists, with support from SCCPHD staff, visually presented the Our Voice methods and results to their stakeholders and brainstormed ideas for realistic local improvements. In subsequent meetings initiated by the citizen scientists across the school year, they continued to explore ways of improving the school environment in addition to instituting action plans to address key concerns. 
In School B, per standard practice in the County, SCCPHD staff reviewed and analyzed data from the SRTS observational assessment tools and developed a slide show with photos that displayed data from the environmental assessments at this school's stakeholder meeting. Consistent with SRTS program methods in this locale, information was presented by the SCCPHD staff and included brainstorming of ideas and prioritization with key stakeholders. As per the standard SRTS protocol, this constituted the only meeting in this school.

\section{Project assessments}

\section{SRTS program engagement assessment}

In order to measure program engagement at both elementary schools during this initial SRTS year, the frequency of meetings, events, and activities were documented over the 9-month school period from September 2015 to May 2016 by SCCPHD contractors and SRTS Parent Coordinators who reported to school staff and the SCCPHD. Tracked events included SRTS meetings and planning activities, educational activities, and "encouragement" events (see Table 2).

\section{Student travel mode assessment}

At the beginning and end of the school year, SCCPHD staff sent a packet of standard SRTS Student Travel Tally forms to each elementary school [24, 25]. For both schools, teachers were instructed to collect the Travel Tally forms at least twice during the Tuesday to Thursday period of the week of September 15-17 (beginning of the school year) and during the Tuesday to Thursday period of the week of May 3-5 (end of the school year), with the tally data averaged within each time period for each school. Because the travel tally weeks occurred at the same time for both schools, extraneous factors that could have potentially affected walking/biking to school (e.g., weather) were held constant. Teachers were responsible for surveying their students on whether they walked, biked, or rode in a vehicle to school on the above specified days during each travel tally week. SCCPHD staff retrieved the surveys and entered the information onto the SRTS National Data Center website, which is a secure online central database system.

\section{Exploring maintenance of program engagement activities during the following year}

As is common practice for SRTS, schools are encouraged to continue to work on SRTS action plans and activities developed during the initial program year. SCCPHD staff continued to provide technical assistance and resources as needed, and track numbers and types of SRTS program activities that occurred.

\section{Data analysis}

Between-school differences in the percentage of children walking/biking to school at the beginning and end of the year were evaluated using Pearson's chi-square test, with alpha set at .05, two-tailed. To capture the differences in baseline proportions and enhance the robustness of the data analysis for the student travel tally data, a "difference in differences" (DID) analytic procedure [26] also was conducted to evaluate the additional treatment effect of the Our Voice intervention on the proportions of student who walked/biked to school. DID was conducted by using the following logistic model with a simulated dataset where the total numbers of students and travel tally data were applied as parameters.

$$
\operatorname{logit}(w b=1)=\beta_{0}+\beta_{t} t+\beta_{e} o v+\beta_{*} t * o v
$$

where $w b$ is walk/bike, $t$ is for time (baseline/pre vs. endline/post), and ov is for Our Voice intervention (SRTS + Our Voice vs. SRTS only). DID is $\beta_{*}$, the interaction term coefficient. $\beta_{*}$ is then exponentiated to obtain the odds ratio or effect size. All statistical analyses were performed using STATA 15.0 Statistical Software [27].

The total number of SRTS program engagement activities occurring across the year in each school is presented in a descriptive format (Tables 2 and 4).

\section{Results}

\section{School descriptions}

The two elementary schools, which included grades kindergarten to fifth grade, had similar characteristics with respect to general student population size (total student population $=740$ in School A and 730 in School B) and student gender distribution ( $50 \%$ each of males and females). Based on the 2015 parental survey, the two schools were also generally similar with respect to the majority of students being driven to and from school in a family vehicle ( $82 \%$ in School A and $71 \%$ in School B), the proportion of parents reporting that their child's school encouraged walking or biking to and from school (36\% in School A and 33\% in School B), and parental perceptions that walking/biking to school was healthy for their child (83\% in School A and 89\% in School B). With respect to general socioeconomic characteristics, California Department of Education enrollment statistics indicated that during the 2015-16 school year, $16.5 \%$ of children in School A were non-Hispanic white, $67.8 \%$ were of Latino or Hispanic descent, and 5.8\% were of Asian descent. Based on household income, $48.2 \%$ of children in School A were eligible for the National Free or Reduced-price School Lunch Program based on household income. Meanwhile, In School B, 47.1\% were non-Hispanic white, $39.4 \%$ were of Latino or Hispanic descent, and $7.9 \%$ were of Asian descent. Based on 
household income, $22.4 \%$ of children in School B were eligible for the National Free or Reduced-price School Lunch Program based on household income.

\section{Pre-SRTS program SCCPHD school transportation data}

September, 2015 pre-program travel mode data collection conducted on the total School A student population $(N=$ $740)$ revealed that $94.7 \%(n=701)$ of all students traveled to school by car, $5.0 \%(n=37)$ walked to school, and $0.3 \%$ $(n=2)$ traveled to school by bicycle. Of the total School B student population $(N=730), 82.3 \%(n=601)$ of all students traveled to school by car, $17.0 \%(n=124)$ walked to school, and $0.7 \%(n=5)$ arrived at school by bicycle. These percentages indicate that pre-intervention walking or biking to School A was significantly lower at the beginning of the school year relative to walking or biking to School B, with a between-school chi-square comparison for the above percentages of $X^{2}=8.3[\mathrm{df}=1], P=.004$.

\section{Citizen science participant demographics}

Citizen science participant demographic information was collected in post-assessment surveys from School A parent participants. Participants had an age range of 46-49 years, and five of the six were women. When asked about race/ethnicity, four identified as Hispanic White and two as non-Hispanic White or Other. Demographic information was not available for adults participating in School B SRTS assessments because the standard SRTS process did not involve such surveys.

\section{Identification of school environment challenges through the observational audits}

From the Our Voice citizen scientist discussions based on the DT photographs and audio narratives collected at School A, the top three environmental barriers to walking/ biking to school identified by the citizen scientists were concerns with traffic flow, sidewalk issues, and a specific problematic intersection. In School B, the SRTS environmental audit tool indicated somewhat higher (worse) scores on driver behaviors, ease of street crossings, ease of bicycling, and parent support (all received mean scores of 3 on the 1 - to 7 -point scale).

\section{Stakeholder engagement in SRTS at each school}

The School A SRTS + Our Voice stakeholder meeting engaged 13 stakeholders from seven different community sectors (see Table 1). School B's standard SRTS advocacy meeting engaged 12 stakeholders from six different sectors (Table 1).

\section{SRTS program engagement activities}

As summarized in Table 2, School A reported twice as many SRTS team meetings and action planning activities $(n=8)$ compared to School B $(n=4)$. These included the
Table 1 Stakeholder sectors represented at community stakeholder advocacy meetings at the two elementary schools

\begin{tabular}{lll}
\hline Stakeholder Sectors & $\begin{array}{l}\text { School A (SRTS } \\
+ \text { Our Voice) }\end{array}$ & School B (SRTS Alone) \\
\hline Teachers & 0 & 0 \\
School Administration & 1 & 1 \\
Students & 0 & 0 \\
Parents & 3 & 5 \\
Public Works & 1 & 0 \\
Public Health & 3 & 2 \\
Law Enforcement & 1 & 1 \\
Bike Advocate & 2 & 1 \\
School District & 0 & 0 \\
Research team & 2 & 0 \\
Community Members & 0 & 2 \\
\hline
\end{tabular}

initiation of monthly SRTS task force meetings at School A and a 3-year Safe Routes to School Action Plan generated by parents. A team of six School A parents became involved in managing the SRTS program, while at School $\mathrm{B}$, parent volunteers could not be identified, so a teacher took on the responsibility of coordinating SRTS activities. School A also reported more SRTS events than School B (Table 2), and as a result of increased interest in biking to school, installed two additional bike racks. No such environmental changes were observed at School B.

The frequency of overall activities noted above favored the SRTS + Our Voice school, which had a $48 \%$ greater number of SRTS program engagement activities than the SRTS-Alone school (see Table 2).

\section{Changes in SRTS student travel mode data across year 1}

As summarized in Table 3, at School A, the SRTS tally forms capturing the entire student population indicated that walking/biking to school increased from 5.3\% (5.0\% walked, $0.3 \%$ biked) to $30 \%$ ( $22.0 \%$ walked, $8.0 \%$ biked), while walking/biking rates at School B, collected in the same manner, decreased slightly from $17.7 \%$ ( $10.8 \%$ walked, $0.7 \%$ biked) to $15.0 \%$ (13.0\% walked, $2.0 \%$ biked). Pearson's chi-square test indicated that the between-school difference was statistically significant $\left(X^{2}=12.3[\mathrm{df}=1], P<.001\right)$, with endpoint walk/ bike rates twice as high in School A relative to B. Furthermore, "difference in differences" (DID) modeling indicated an effect size of $9.34(P<0.001 ; 95 \%$ confidence interval $=$ 5.92-14.67), which indicates that the SRTS + Our Voice program, compared to the SRTS-Alone program, increased the odds of students walking/biking to school by a factor of 9.34 .

\section{Maintenance of SRTS program engagement activities following the initial SRTS year}

Table 4 summarizes the SRTS program engagement activities occurring at each school during the following school 
Table 2 Community engagement at the two elementary schools across the initial 9-month school period (Fall 2015 to Spring 2016)

\begin{tabular}{|c|c|c|c|}
\hline Engagement metrics & Definitions & School A (SRTS + Our Voice) & School B (SRTS Alone) \\
\hline \multicolumn{4}{|l|}{ Meetings and Action Planning (counts) } \\
\hline Community meeting & Meeting to identify and prioritize key issues & 1 & 0 \\
\hline Stakeholder meeting & Meeting to present findings to local stakeholders & 1 & 1 \\
\hline SRTS team meeting & $\begin{array}{l}\text { Follow-up meetings involving citizen scientists and } \\
\text { community residents interested in SRTS }\end{array}$ & 5 & 2 \\
\hline Action Plan & $\begin{array}{l}\text { Action plan developed by community residents to } \\
\text { further local SRTS }\end{array}$ & 1 & 1 \\
\hline Total meetings & & 8 & 4 \\
\hline \multicolumn{4}{|l|}{ Encouragement Events (counts) } \\
\hline Walk/bike events & $\begin{array}{l}\text { School-wide events such as National Bike to School } \\
\text { Day and Bike Education Days }\end{array}$ & 2 & 1 \\
\hline Walk \& Roll Days & $\begin{array}{l}\text { Days set aside to encourage walking and biking to } \\
\text { school }\end{array}$ & 5 & 2 \\
\hline Walking school bus & $\begin{array}{l}\text { A walking school bus involves a group of students } \\
\text { and parents walking together on the way to school } \\
\text { in the morning }\end{array}$ & 5 & 2 \\
\hline Total encouragement events & & 12 & 5 \\
\hline \multicolumn{4}{|l|}{ Educational Activities (counts) } \\
\hline $\begin{array}{l}\text { In-class educ. Activity: } \\
\text { Grades K, 2nd, 4th, or 5th }\end{array}$ & $\begin{array}{l}\text { Educational activities supported by SRTS in a } \\
\text { classroom setting }\end{array}$ & 12 & 13 \\
\hline Bike Rodeo & Event that includes biking lessons and safety tips & 0 & 1 \\
\hline Family Fun Bike Night / Bike Repair & $\begin{array}{l}\text { Event supported by SRTS to teach students about } \\
\text { biking and bicycle repair }\end{array}$ & 1 & 0 \\
\hline $\begin{array}{l}\text { Traffic safety educ. \& helmet } \\
\text { distribution }\end{array}$ & $\begin{array}{l}\text { Event supported by SRTS to teach students about } \\
\text { traffic safety and distribute helmets }\end{array}$ & 1 & 0 \\
\hline Total educational activities & & 14 & 14 \\
\hline OVERALL NUMBER OF SRTS ACTIVITIES & & 34 & 23 \\
\hline
\end{tabular}

year (Fall, 2016 to Spring, 2017). As shown in this table, School A had an almost three-fold greater number of SRTS-related meetings and activities relative to School B.

\section{Investigation 2: Exploring the feasibility of the SRTS + Our Voice program in a middle school environment}

\section{Methods}

To further explore the feasibility of adding Our Voice to SRTS activities, the SRTS + Our Voice intervention was initiated at a middle school in Gilroy (student population size $=855)$ which had not participated previously in SCCPHD SRTS programming and for which SCCPHD was planning an SRTS intervention during a time period similar to that of the elementary schools (Fall, 2015 to Spring 2016). The middle school students themselves, rather than parents, served as citizen scientists. Participants from the middle school (grades 6 to 8), consisted of students and school faculty, recruited through a student leadership group, who were interested in engaging with SRTS. Human subject approvals were obtained from the Institutional Review Board (IRB) at Stanford University and from the IRB at the SCCPHD.

The SCCPHD SRTS program was generally similar to the program conducted at the elementary schools, with the exception that no in-class SRTS educational activities were delivered. Specific walking locations of particular relevance to school access were selected by SCCPHD staff in which to conduct the Our Voice DT assessments. The citizen scientists were 26 middle school students.

The middle school intervention and assessment methods were similar to those conducted at elementary school A and included the use of the DT mobile app (by the middle school students) to capture relevant barriers to and facilitators of active transport to school. The community meetings followed the same structure as those at elementary school A, (i.e., group-based DT photo categorization, discussion, and consensus-building around prevalent barriers to walking/biking to school; a subsequent student citizen scientist presentation of their data and insights to relevant local stakeholders with whom they brainstormed potential solutions and next steps). 
Table 3 One-year changes in SRTS student travel mode data

\begin{tabular}{|c|c|c|c|c|c|c|c|}
\hline & \multicolumn{2}{|c|}{ School A (SRTS + Our Voice) } & \multirow[b]{2}{*}{ post-pre difference } & \multicolumn{2}{|c|}{ School B (SRTS only) } & \multirow[b]{2}{*}{ post-pre difference } & \multirow[b]{2}{*}{ diff in diffs (DID) } \\
\hline & pre & post & & pre & post & & \\
\hline Traveled by car - \% & $94.7 \%$ & $70.0 \%$ & $-24.7 \%$ & $82.3 \%$ & $85.0 \%$ & $2.7 \%$ & $-27.4 \%$ \\
\hline Walked - \% & $5.0 \%$ & $22.0 \%$ & $17.0 \%$ & $17.0 \%$ & $13.0 \%$ & $-4.0 \%$ & $21.0 \%$ \\
\hline Bicycled - \% & $0.3 \%$ & $8.0 \%$ & $7.7 \%$ & $0.7 \%$ & $2.0 \%$ & $1.3 \%$ & $6.4 \%$ \\
\hline Walked/bicycled - \% & $5.3 \%$ & $30.0 \%$ & $24.7 \%$ & $17.7 \%$ & $15.0 \%$ & $-2.7 \%$ & $27.4 \%$ \\
\hline
\end{tabular}

SRTS program engagement measurement and SRTS Student Travel Mode data collection followed the same procedures as described earlier for the elementary school evaluation.

\section{Results}

\section{School description}

California Department of Education enrollment statistics for 2015-2016 reported that $25.3 \%$ of middle school students were non-Hispanic white, $58.4 \%$ were of Latino or Hispanic descent, and $4.9 \%$ were of Asian descent. Based on household income, 47.6\% were eligible for the National Free or Reduced-price School Lunch Program.

\section{Pre-SRTS program school transportation data}

Parental attitude and behavior survey data gathered in 2015 by the SCCPHD SRTS Program revealed that of the 855 parents surveyed, $86.2 \%(n=737)$ reported that their children traveled to school by car, $10.4 \%$ $(n=89)$ walked to school, and $3.4 \%(n=29)$ biked to school.

\section{Our Voice participant demographics}

Seventeen of the 26 students participating in Our Voice middle school activities completed demographic surveys. Reasons for survey non-completion included limited time allowed to complete the surveys in class and students failing to return the survey.

Table 4 Community engagement at the two elementary schools across the subsequent 9-month school period (Fall 2016 to Spring 2017)

\begin{tabular}{|c|c|c|c|}
\hline Engagement metrics & Definitions & School A (SRTS + Our Voice) & School B (SRTS Alone) \\
\hline \multicolumn{4}{|c|}{ Meetings and Action Planning (counts) } \\
\hline Community meeting & Meeting to identify and prioritize key issues & 0 & 0 \\
\hline Stakeholder meeting & Meeting to present findings to local stakeholders & 1 & 0 \\
\hline SRTS team meeting & $\begin{array}{l}\text { Follow-up meetings involving citizen scientists and community } \\
\text { residents interested in SRTS }\end{array}$ & 7 & 2 \\
\hline Action Plan & $\begin{array}{l}\text { Action plan developed by community residents to further SRTS } \\
\text { efforts in their local school }\end{array}$ & 1 & 1 \\
\hline Total meetings & & 9 & 3 \\
\hline \multicolumn{4}{|l|}{ Encouragement Events (counts) } \\
\hline Walk/bike events & $\begin{array}{l}\text { School-wide events such as National Bike to School Day and } \\
\text { Bike Education Days }\end{array}$ & 2 & 1 \\
\hline Walk \& Roll Days & Days set aside to encourage walking and biking to school & 16 & 2 \\
\hline Walking school bus & $\begin{array}{l}\text { A walking school bus involves a group of students and parents } \\
\text { walking together on the way to school in the morning }\end{array}$ & 16 & 1 \\
\hline Total encouragement events & & 34 & 4 \\
\hline \multicolumn{4}{|l|}{ Educational Activities (counts) } \\
\hline $\begin{array}{l}\text { In-class educ. Activity: Grades } \\
\text { K, 2nd, 4th, 5th }\end{array}$ & Educational activities supported by SRTS in a classroom setting & 13 & 13 \\
\hline Bike Rodeo & Event that includes biking lessons and safety tips & 0 & 0 \\
\hline $\begin{array}{l}\text { Family Fun Bike Night / } \\
\text { Bike Repair }\end{array}$ & $\begin{array}{l}\text { Event supported by SRTS to teach students about biking and } \\
\text { bicycle repair }\end{array}$ & 1 & 0 \\
\hline $\begin{array}{l}\text { Traffic safety educ. \& helmet } \\
\text { distribution }\end{array}$ & $\begin{array}{l}\text { Event supported by SRTS to teach students about traffic safety } \\
\text { and distribute helmets }\end{array}$ & 1 & 0 \\
\hline \multicolumn{2}{|l|}{ Total educational activities } & 15 & 13 \\
\hline \multicolumn{2}{|c|}{ OVERALL NUMBER OF SRTS ACTIVITIES } & 58 & 20 \\
\hline
\end{tabular}


Participants had an age range of $12-13$ years and consisted of 12 girls and five boys. When asked about race/ethnicity, six self-identified as non-Hispanic white.

\section{Identification of school environment challenges through the observational audits}

The top three barriers to walking/biking to school identified by citizen scientists via the DT and discussed during the first Our Voice meeting were traffic violations, safety concerns, and lack of crosswalks. Additional barriers included lack of pedestrian/bicyclist education, traffic congestion, lack of appropriate and visible traffic signs, trash, broken sidewalks, and lack of bike racks.

\section{Stakeholder engagement in SRTS + Our Voice activities}

The stakeholder advocacy meetings engaged the middle school students as co-presenters who described their findings to relevant stakeholders. A total of 16 stakeholders from nine different sectors participated, including from the school administration, Gilroy City Public Works and Police Departments, and non-governmental organizations (i.e., the Silicon Valley Bicycle Coalition).

\section{SRTS program engagement activities}

A total of 14 engagement activities were recorded across the school year, including four SRTS team meetings. SRTS educational activities included a school-wide bike-to-school education/encouragement day (40 students), and a traffic safety education and helmet distribution activity (75 students). The middle school also incorporated peer-to-peer student education (e.g., peer leaders demonstrated helmet fitting).

The SRTS + Our Voice intervention created opportunities to participate in new youth advocacy and outreach activities. For example, students were invited to speak at a Youth for Environment and Sustainability Conference in Berkeley, California and present their findings to the City of Gilroy Bike and Pedestrian Commission. Students continued to discuss SRTS topics throughout the school year as part of their monthly leadership group meetings.

Students also discussed SRTS-relevant environmental and infrastructure changes with key stakeholders during the advocacy meetings. Possible changes included a City Public Works Department evaluation of the flow of bikes, pedestrians, and cars entering and leaving the school area to increase safety. However, with the departure of the City's Public Works engineer, such infrastructure changes were unable to be pursued at that time. Subsequently, SCCPHD staff reached out to the local Bicycle and Pedestrian Commission to build collaborations for such SRTS activities with youth advocacy support.

\section{Changes in SRTS student travel mode data across the school year}

Pre-post SCCPHD-collected travel mode tally data indicated that walking/biking to school rates from September 2015 to the end of the school year in 2016 remained at $19 \%$ at both time points (15.5\% walked, $3.5 \%$ biked). A year after the SRTS assessments, it was observed that a new cohort of students had continued the discussion of SRTS topics and was planning activities to further promote walking and biking to school.

\section{Discussion}

A commonly reported issue in SRTS programming is difficulty attracting community engagement and ongoing participation. Adding the Our Voice citizen science approach to the initial implementation of a SRTS elementary school program was associated with a significant increase in reported walking/biking to school relative to a comparison school which did not receive this additional intervention. The SRTS + Our Voice intervention was also generally associated with higher levels of engagement among elementary school parents across a 21-month period. Anecdotal observations by the SCCPHD staff members facilitating the SRTS programs suggested that the potential mechanisms that may have led to this increased engagement included an enhanced sense of ownership over local data, an increased interest in SRTS facilitated by directly capturing local barriers and facilitators with an innovative mobile app, and the community members' role as co-presenters at stakeholder meetings. While it was beyond the scope of the current pilot investigation to capture such mechanisms in a more systematic way, Our Voice studies conducted in other community settings (e.g., neighborhoods) suggest that the civic engagement engendered by this type of citizen science approach may increase such mechanisms [11, 17, 18].

The size of the relative increase in reported walking/biking to school in the elementary school receiving SRTS + Our Voice (from 5.5 to 30\%) was larger than what is typically reported in the SRTS literature (i.e., from 12.9 to 17.6\%) [7]. It is possible that some source of measurement error affected these data, although standard SRTS tally procedures were used [25], and all students in each elementary school were included in these tallies. Given the preliminary nature of this investigation, it is important that the SRTS + Our Voice intervention procedures be replicated in other schools to better ascertain where the true impact of the additional Our Voice citizen science component may lie.

Results from applying the SRTS + Our Voice approach in a middle school suggest that youth as well as adults can fully participate in this type of citizen science process. Incorporating students in the assessment process proved successful in achieving high initial engagement (26 participating students), compared to citizen science engagement in the elementary school (six participating parents). 
SCCPHD staff also reported that engaging youth in the stakeholder presentations yielded more compelling stories, with the students themselves advocating for the improvement of their school environment. However, the middle school setting also presented structural challenges in carrying out some aspects of SRTS (e.g., teachers had limited time to supervise group meetings). While the students were invited to present at a youth environmental sustainability conference, they were unable to attend due to liability concerns. Despite these institutional barriers, the middle school students have continued to engage with the SRTS program. The initial cohort of middle school citizen scientists, who have moved on to high school, passed on responsibilities to a new cohort of middle school students who continue to lead school-based SRTS activities.

A large-scale study of 5-year SRTS program effects across 4 U.S. regions indicated that engineering and related environmental changes were associated with an $18 \%$ relative increase in walking and biking to school [6]. While the SRTS + Our Voice elementary school program resulted in at least one environmental change (i.e., additional bike racks), most activities involved new educational and motivational programs. The same large-scale study reported that such educational and encouragement programs have led to a $25 \%$ increase in walking and biking over a 5-year period [6]. In contrast, the middle school included specific targeting of local built environments and policies aimed at safer walking/biking to school. These included proposed solutions to improve the school's traffic and drop-off policies. Unfortunately, with the departure of a key stakeholder in this area (the City's Public Works engineer), such solutions were unable to be pursued during the project period. While environmental and policy changes may take longer to implement, they could potentially translate into more enduring changes in SRTS behaviors over time [28].

\section{Limitations}

While the results of this first-generation investigation are promising, further investigation and replication of the effects of this combined approach in a larger and more diverse number of schools are needed. Among the limitations of the study design is the fact that the SRTS county health department initiated the SRTS program in School A approximately 6 weeks earlier than School B. This somewhat longer time period could have conceivably influenced the differential results favoring School A, which received the additional Our Voice intervention. During this 6-week start period, School A SRTS activities consisted of one Santa Clara County Public Health Department-led SRTS media day occurring on October 7, 2015. The Public Health Department staff promoted walking and biking to the school on that day. While it is not possible, given the study design, to determine the specific impacts of this one-day event on the differential walk/bike tallies observed at the end of the school year, there is little evidence in the literature indicating that a one-day SRTS event at the beginning of the school year could have such a substantial effect nine months later [7]. In addition, we observed even stronger betweenschool differences in SRTS engagement activities during the follow-up year when there was no difference in the SRTS program start date.

It is also possible that the larger proportions of lower income and racial/ethnic minorities in School A could have in some way resulted in the significant differences in walk/ bike patterns shown across the school year in School A vs. B independent of the Our Voice intervention. However, prior SRTS research on U.S. schools that have larger proportions of Hispanic as well as lower-income students typically have found generally higher rates of walking/biking to school in those populations [7, 29], which was not the case at baseline in School A. This might have been due, at least in part, to the less urbanized nature of the school district under study relative to a number of other investigations, as well as the observation that lower-income Hispanic children living in western areas of the U.S. are more likely to live in less safe neighborhoods with poorer street environments [30]. These potential factors deserve further systematic investigation [7]. Similarly, while there could have been initial differences in parental and school-based readiness between the two elementary schools, pre-intervention parental survey data related to parental perceptions that their child's school encouraged walking/biking to and from school and that walking/biking to school was healthy for their child were similar. In addition, the significant increase in walking/biking to school in the SRTS + Our Voice school, which had significantly lower baseline walking/biking rates relative to the SRTS-Alone school, was substantially larger than what one might typically expect if simply a "regression to the mean" phenomenon was operating.

Systematically tracking behavior change of this type across more extended time periods also presents challenges. The SRTS walking/biking travel mode tally required teachers to facilitate data collection, which can lead to teacher burden. Given the inevitable variability in school populations, policies, and resources that occur over time, SRTS programs may need to track walking/biking rates over much longer time spans (e.g., 5-10 years) using more rigorous experimental designs to accurately determine significant behavior changes [5]. An important goal of such programs is to ensure that the community does not disengage when change does not happen immediately.

\section{Conclusions}

This first-generation study suggests that the addition of a technology-enabled citizen science process to a standard 
elementary school SRTS program was associated with higher levels of community engagement and reported walking/biking to school compared to SRTS alone. The results also indicate that this approach is feasible to employ in a middle school setting where students can participate as the "citizen scientists". The findings suggest that further investigation of this citizen science approach in the elementary and middle school settings is warranted.

\section{Abbreviations}

DT: Discovery Tool; SCCPHD: Santa Clara County Public Health Department; SRTS: Safe Routes to School

\begin{abstract}
Acknowledgements
This work was made possible thanks to a partnership between the Our Voice Initiative at Stanford University School of Medicine and the Santa Clara County Public Health Department. SCCPHD support was integral to the success of the SRTS programs and the SRTS Our Voice research projects. Technical assistance with data input was provided by Naina Ahuja and Jaqueline Botts, and assistance with the SCCPHD SRTS program was provided by Tonya Veitch, BS. Additional guidance with data analysis was provided by Lorene Nelson, PhD and Michael Baiocchi, PhD. We also want to acknowledge our partners in this work, the dedicated citizen scientists who were the driving force behind this community-based participatory research. In addition, we thank the representatives of the Gilroy Unified School District, Gilroy Public Works Department, Gilroy Police Department, and the Silicon Valley Bicycle Coalition for their support throughout this project.
\end{abstract}

\section{Funding}

Financial support for the Our Voice projects in Santa Clara County came from the Wellness Living Laboratory (WELL) at Stanford. Foundational funding for WELL was provided by Amway via an unrestricted gift through the Nutrilite Health Institute Wellness Fund. Dr. King was supported in part by The Robert Wood Johnson Foundation Grant ID\#7334, NIH/National Cancer Institute grants 5R01CA211048 and P20CA217199, NIH/National Institute of Diabetes and Digestive and Kidney Diseases grant 5R01DK102016, Silicon Valley Community Foundation award \#101518, a grant from the Discovery Innovation Fund in Basic Biomedical Sciences from Stanford University, US Public Health Service Grant 1U54EB020405 supporting The National Center for Mobility Data Integration and Insight (PI: S. Delp), and US Public Health Service Grant 1U54MD010724 (PI: M. Cullen). Dr. Hua was supported by an $\mathrm{NIH/NHLBI}$ institutional postdoctoral training grant (T32 HL007034). The funding sources played no role in study design, collection, analysis or interpretation of data, or writing of the manuscript.

\section{Availability of data and materials}

Data and materials are available from the corresponding author on reasonable request.

\section{Authors' contributions}

NR contributed to the investigation design and methods, participated in aspects of data collection and interpretation of results, and helped to draft and edit portions of the manuscript and develop Tables. AA contributed to the investigation design and methods, and participated in aspects of data collection, selection of measures, interpretation of results, and editing of manuscript drafts. AK contributed to the the investigation design and methods, and participated in aspects of data collection, selection of measures interpretation of results, and editing of manuscript drafts. $\mathrm{JH}$ conducted data analysis and participated in the interpretation of results, developed tables, and participated in the editing of manuscript drafts. BB contributed to the investigation design and methods and participated in the selection of measures, interpretation of results, and editing of manuscript drafts. SW contributed to the investigation design and methods and participated in the interpretation of results and editing of manuscript drafts. ACK conceived of the investigation design and methods, led the selection of measures, interpreted study results, and wrote and edited manuscript drafts. All authors read and approved the final manuscript.

\section{Ethics approval and consent to participate}

Human subject approvals were obtained from the Institutional Review Boards (IRBs) at the Santa Clara County Public Health Department and Stanford University. Written informed consent was obtained from all adult participants, and for participants under the age of 16 years, written informed assent from the participants and written informed consent from their parents/guardians were obtained.

\section{Consent for publication}

Not applicable.

\section{Competing interests}

The authors declare that they have no competing interests.

\section{Publisher's Note}

Springer Nature remains neutral with regard to jurisdictional claims in published maps and institutional affiliations.

\section{Author details}

${ }^{1}$ Stanford Prevention Research Center, Department of Medicine, Stanford University School of Medicine, Stanford, CA 94305, USA. '2 Santa Clara County, CA Public Health Department, Center for Chronic Disease and Injury Prevention, San Jose, CA 95126, USA. ${ }^{3}$ Division of Epidemiology, Department of Health Research and Policy, Stanford University School of Medicine, Stanford, CA 94305, USA. ${ }^{4}$ Stanford Prevention Research Center, 1070 Arastradero Road, Suite 100, Palo Alto, CA 94304-1334, USA.

Received: 9 May 2018 Accepted: 19 February 2019

Published online: 01 March 2019

\section{References}

1. Kohl HW, Cook HD. Educating the student body: taking physical activity and physical education to school. Washington, DC: food and nutrition board, institute of Medicine; 2013.

2. McDonald NC. Active transportation to school: trends among U.S schoolchildren, 1969-2001. Am J Prev Med. 2007:32(6):509-16.

3. National Safe Routes to School, 2017 [http://www.saferoutesinfo.org/]

4. Lee MC, Orenstein MR, Richardson MJ. Systematic review of active commuting to school and childrens physical activity and weight. J Phys Act Health. 2008;5(6):930-49.

5. McDonald N. Impact of safe routes to school programs on walking and biking. In: . San Diego, CA: Active living research: Active Living Research. p. 2015.

6. McDonald NC, Steiner RL, Lee C, Rhoulac ST, Zhu X, Yang Y. Impact of the safe routes to school program on walking and bicycling. J Am Planning Assoc. 2014:80(2):153-67.

7. Stewart O, Moudon AV, Claybrooke C. Multistate evaluation of safe routes to school programs. Am J Health Promot. 2014;28(3 Suppl):S89-96.

8. saferoutesinfo.org: SRTS Guide: History of Safe Routes to School. In.

9. Macridis S, Bengoechea EG. Adoption of safe routes to school in Canadian and the United States contexts: best practices and recommendations. J Sch Health. 2015.

10. McDonald NC, Steiner RL, Palmer WM, Bullock AN, Sisiopiku VP, Lytle BF. Costs of school transportation: quantifying the fiscal impacts of encouraging walking and bicycling for school travel. Transportation. 2016;43(1):159-75.

11. King AC, Winter SJ, Sheats $J$, Rosas LG, Buman MP, Salvo D, Rodriguez NM, Seguin RA, Moran M, Garber R, et al. Leveraging citizen science and information technology for population physical activity promotion. Translat J ACSM. 2016:1(4):30-44

12. Buman MP, Winter SJ, Sheats JL, Hekler EB, Otten JJ, Grieco LA, King AC. The Stanford healthy neighborhood discovery tool: a computerized tool to assess active living environments. Am J Prev Med. 2013;44(4):e41-7.

13. Buman MP, Winter SJ, Baker C, Hekler EB, Otten JJ, King AC. Neighborhood eating and activity advocacy teams (NEAAT): engaging older adults in policy activities to improve food and physical environments. Transl Behav Med. 2012;2(2):249-53

14. Seguin RA, Morgan EH, Connor LM, Garner JA, King AC, Sheats JL, Winter SJ, Buman MP. Rural food and physical activity assessment using an electronic tablet-based application, New York, 2013-2014. Prev Chronic Dis. 2015;12:E102. 
15. Hinckson E, Schneider M, Winter SJ, Stone E, Puhan M, Stathi A, Porter MM, Gardiner PA, Dos Santos DL, Wolff A, et al. Citizen science applied to building healthier community environments: advancing the field through shared construct and measurement development. Int I Behav Nutr Phys Act. 2017;14(1):133.

16. Rosas LG, Salvo D, Winter SJ, Cortes D, Rivera J, Rodriguez NM, King AC. Harnessing technology and citizen science to support neighborhoods that promote active living in Mexico. J Urban Health. 2016;93(6):953-73.

17. Winter SJ, Goldman Rosas L, Padilla Romero P, Sheats JL, Buman MP, Baker C, King AC. Using citizen scientists to gather, analyze, and disseminate information about neighborhood features that affect active living. J Immigr Minor Health. 2015.

18. Sheats JL, Winter SJ, Romero PP, King AC. FEAST: empowering community residents to use technology to assess and advocate for healthy food environments. J Urban Health. 2017:94(2):180-9.

19. Moran MR, Werner P, Doron I, HaGani N, Benvenisti Y, King AC, Winter SJ, Sheats JL, Garber R, Motro H, et al. Exploring the objective and perceived environmental attributes of older adults' neighborhood walking routes: a mixed methods analysis. J Aging Phys Act. 2016:1-36.

20. International Affairs Office. Organization of U.S. education: the school level. Washington, DC: U.S. Network for education information, U.S. department of Education; 2008.

21. U.S. Census Bureau. U.S. Census 2015. In. Washington, DC: U.S. Census Bureau; 2015.

22. Census Bureau US. 2010 Census and 2010-2014 American community survey 5-year estimates. In. Washington, DC: U.S. Census Bureau; 2010

23. National Center for Safe Routes to Schools: National Center for Safe Routes to School Parent Survey. www.saferoutesinfo.org/programs-tools/, accessed January 5, 2018

24. Corman E, Kawaguchi A, Pollet I, Swent R, Veitch T, Ward S: Safe routes to school coordinator manual: A How-to guide for promoting walking and rolling at your school. In. Edited by Network TSC. Santa Jose, CA: Santa Clara County Public Health Department; 2014

25. National Center for Safe Routes to School Evaluation: student in-class travel tally [www.saferoutesinfo.org/program-tools/evaluation-student-class-travel-tally].

26. Stock JH, Watson MW. Introduction to econometrics. 2nd ed. Boston, MA: Addison Wesley; 2007

27. StataCorp: Stata Statistical Software: Release 15. College Station, TX: StataCorpLLC; 2017

28. Chen P, Jiao J, Xu M, Gao X, Bischak C. Promoting active student travel: a longitudinal study. J Transport Geography. 2018;70:265-74.

29. McDonald NC. Critical factors for active transportation to school among low-income and minority students. Evidence from the 2001 National Household Travel Survey. Am J Prev Med. 2008;34(4):341-4.

30. Zhu X, Lee C. Walkability and safety around elementary schools economic and ethnic disparities. Am J Prev Med. 2008;34(4):282-90.

Ready to submit your research? Choose BMC and benefit from:

- fast, convenient online submission

- thorough peer review by experienced researchers in your field

- rapid publication on acceptance

- support for research data, including large and complex data types

- gold Open Access which fosters wider collaboration and increased citations

- maximum visibility for your research: over $100 \mathrm{M}$ website views per year

At $\mathrm{BMC}$, research is always in progress.

Learn more biomedcentral.com/submissions 